\title{
Oxygen-ozone immunoceutical therapy in COVID-19 outbreak: facts and figures
}

\author{
Giovanni Ricevuti, ${ }^{1}$ Marianno Franzini, ${ }^{2}$ Luigi Valdenassi ${ }^{3}$ \\ ${ }^{1}$ Department of Drug Science, University of Pavia, Italy, High School in Oxygen Ozone Therapy, University of Pavia; \\ ${ }^{2}$ SIOOT International, Comunian Clinic, Gorle (BG), High School in Oxygen Ozone Therapy, University of Pavia; \\ ${ }^{3}$ SIOOT, Italian Society of Oxygen Ozone Therapy, High School in Oxygen Ozone Therapy, University of Pavia, Italy
}

The problems related to the approach to the outbreak of COVID-19 in the world require that all possible effective treatment options be explored. The clinical criterion of the researcher is not to refuse a priori, but to verify and evaluate the proposals that are made. Italian Society of Oxygen Ozone Therapy (SIOOT) proposed to the Italian ISS (Italian Institute of Health) to use oxygen ozone therapy $\left(\mathrm{O}_{2} \mathrm{O}_{3}\right)$ in patients with COVID-19. The ISS has said on 24 March 2020 that it is possible to use it in the light of scientific considerations:

Although the proposal is supported by a certain rational basis, the data actually available in relation to the proposed indication consist essentially in demonstrating the effectiveness of ozone in killing SARS virus in monkey cells, and clinical experience of the benefit in patients with bronchopulmonia. However, as the proposal appears to be shared and supported by clinical centers experienced in the treatment of viral pneumonia, treatment could, if deemed appropriate, be carried out under the responsibility of the physician, after obtaining the informed consent of the patient. Considering the "experimental" character of the use this indication, which also requires specific medical experience and the availability of appropriate instruments, it is considered appropriate to acquire also the opinion of the Ethics Committee.

Some hospitals in Lombardy, the region most affected by COVID-19 in Italy, have already started its use with initial positive results.

As little is known about $\mathrm{O}_{2} \mathrm{O}_{3}$ in the world, although there is a lot of scientific evidence published in the recent years on the anti-inflammatory, immunomodulatory and organ-protective

\footnotetext{
Correspondence: Prof. Giovanni Ricevuti, Department of Drug Science, University of Pavia, Italy.

E-mail: giovanni.ricevuti@unipv.it

Received for publication: 2 April 2020.

Accepted for publication: 8 April 2020.

${ }^{\circ}$ Copyright: the Author(s), 2020

Licensee PAGEPress, Italy

Ozone Therapy 2020; 5:9014

doi:10.4081/ozone.2020.9014

This article is distributed under the terms of the Creative Commons Attribution Noncommercial License (by-nc 4.0) which permits any noncommercial use, distribution, and reproduction in any medium, provided the original author(s) and source are credited.
}

validity of $\mathrm{O}_{2} \mathrm{O}_{3}$ therapy, we consider useful to follow the suggestions of the article Activating Immunity to Fight a Foe - A New path, by Richard S. Hotchkiss and Steven M. Opal, ${ }^{1}$ and proposing the $\mathrm{O}_{2} \mathrm{O}_{3}$ therapy as immunoceutical therapy according to the indications of the article. The $\mathrm{O}_{2} \mathrm{O}_{3}$ therapy has many biological effects, but the most relevant is its ability to modulate the activation of Nrf2 (an important nuclear message transductor), the downregulation of $\mathrm{NFkB}$, and it also modulates the NLRP3 inflammasome. . $^{2-4}$

In this letter, I wish to present this therapeutic opportunity, outline the important activities of the Oxygen Ozone Therapy $\left(\mathrm{O}_{2} \mathrm{O}_{3}\right)$ and explain the rationale for this treatment in COVID-19 patients.

Spike protein and Angiotensin-Converting Enzyme 2 (ACE2) cell receptors have been identified as putative receptors for SARSCoV-2; they could promote the proliferation of COVID-19 (Figure 1). It is known that these receptors can be blocked with some specific monoclonals but also through the control of $\mathrm{Nrf} 2$ that regulates and blocks the activity of Spike and ACE2. Because $\mathrm{O}_{2} \mathrm{O}_{3}$ acts directly on $\mathrm{Nrf} 2$, stimulating them, it seems very likely that this is the most important physiological mechanism to block endogenous COVID-19 reduplication by preventing contact with putative receptors of SARS-CoV-19.

Oxygen-ozone has a high solubility in plasma and induces formation of two second messengers, $\mathrm{H}_{2} \mathrm{O}_{2}$ and ozonoids and alchenals (Figure 2). ${ }^{5}$ These are the ones who are mainly competent, interacts with the membrain proteins and receptors of the cells, especially the immunocompetent ones, and enter the cells and interact with signal transduction proteins on the nucleus and mitochondria level. ${ }^{6-9}$ The key action mechanism of $\mathrm{O}_{2} \mathrm{O}_{3}$ therapy is its action on proteasome and inflammation cascade, to control inflammatory process, by stimulating the nuclear factor $\mathrm{Nrf} 2$ and by inhibiting nuclear factor NFkB (Figure 3). ${ }^{10,11}$

The $\mathrm{O}_{2} \mathrm{O}_{3}$ therapy can restore the right immune response by stimulating signal transduction molecules via Nrf2 and thus stimulating the nuclear transduction via specific microRNAs restoring the normal antioxidant and immunostimulating reaction. ${ }^{12}$ The action mechanism of $\mathrm{O}_{2} \mathrm{O}_{3}$ therapy has very well summarized by Noel L. Smith et al. in 2017:13 By reacting with Polyunsaturated Fatty Acids (PUFA) and water, $\mathrm{O}_{3}$ creates hydrogen peroxide $\left(\mathrm{H}_{2} \mathrm{O}_{2}\right)$, a Reactive Oxygen Species (ROS). Simultaneously, $\mathrm{O}_{3}$ forms a mixture of Lipid Ozonation Products (LOP).

The LOPs created after $\mathrm{O}_{3}$ exposure include lipoperoxyl radicals, hydroperoxides, malonyldialdeyde, isoprostanes, the ozonide and alkenals, and 4-Hydroxynonenal (4-HNE). Moderate oxidative stress caused by $\mathrm{O}_{3}$ increases activation of the transcriptional factor mediating nuclear factor-erythroid 2related factor 2 (Nrf2). Nrf2's domain is responsible for activat- 
ing the transcription of Antioxidant Response Elements (ARE). Upon induction of ARE transcription, an assortment of antioxidant enzymes gains increased concentration levels in response to the transient oxidative stress of $\mathrm{O}_{3}$. The antioxidants created include, but are not limited to, Superoxide Dismutase (SOD), Glutathione Peroxidase (GPx), Glutathione S-Transferase (GST), Catalase (CAT), Heme Oxygenase-1 (HO-1), NADPHquinone-Oxidoreductase (NQO-1), Heat Shock Proteins (HSP), and phase II enzymes of drug metabolism. Many of these enzymes act as free radical scavengers clinically relevant to a wide variety of diseases.

Masaru Sagai et al. in $2011^{14}$ described the biological responses induced via the activation of Nrf2/ARE with mild oxidative stress $\left(\mathrm{O}_{2} \mathrm{O}_{3}\right.$ therapy) that can be summarized in:

i) Increasing the levels of direct antioxidants, such as GSH, CO, and bilirubin;

ii) Stimulating GSH regeneration via glutathione and thioredoxin reductase;

iii) Increasing the levels of enzymes that detoxify oxidants and electrophils (i.e. catalase, SOD, GPx, GSTr, NADPHQuinone Oxidoreductase (NQO1), HO-1, HSP70, etc);

iv) Increasing the levels of phase II enzymes;

v) Inhibiting cytokine-mediated inflammation via the induction of leukotriene B4 reductase;

vi) Reducing iron overload, and subsequent oxidative stress induced via elevated ferritin; vii) Recognizing, repairing, and removing damaged proteins;

viii) Protection from apoptosis induced via oxidative stress;

ix) Increasing DNA repair activity.

In addition, Jacqueline Diaz-Luis et al. in $2015^{15}$ demonstrated that ozone was able to modulate the phagocytic cells in peripheral blood and the mechanisms on how messengers can activate immunological response leading to the therapeutic biological effects. Furthermore, it was demonstrated that there is a range of ozone concentrations where we can obtain the highest positive results, while lower doses are ineffective and higher doses can produce lower effects. Accordingly, ozone, in a dose-dependent behavior, may stimulate the phagocytic function of the peripheral blood cells.

Another important effect of $\mathrm{O}_{2} \mathrm{O}_{3}$ therapy than can explain its effects in improving the therapeutic approach to COVID-19 infected patients is its important action on NLRP3 inflammasome that is recognized to play a crucial part in the initiation and continuance of inflammation in various diseases. Gang Yu et al. in 2016 demonstrated that the protective effect of ozone therapy was achieved by its anti-inflammatory property through the modulation of the NLRP3 inflammasome. Ozone-oxygen mixture at low concentration could effectively improve organ ischemia-reperfusion that is what happens in the lungs of patients affected by COVID19 infection. ${ }^{16}$

Ischemia-Reperfusion Injury (IRI) is a major cause of lung dysfunction during many pathological diseases. Zhiwen Wang et al. in

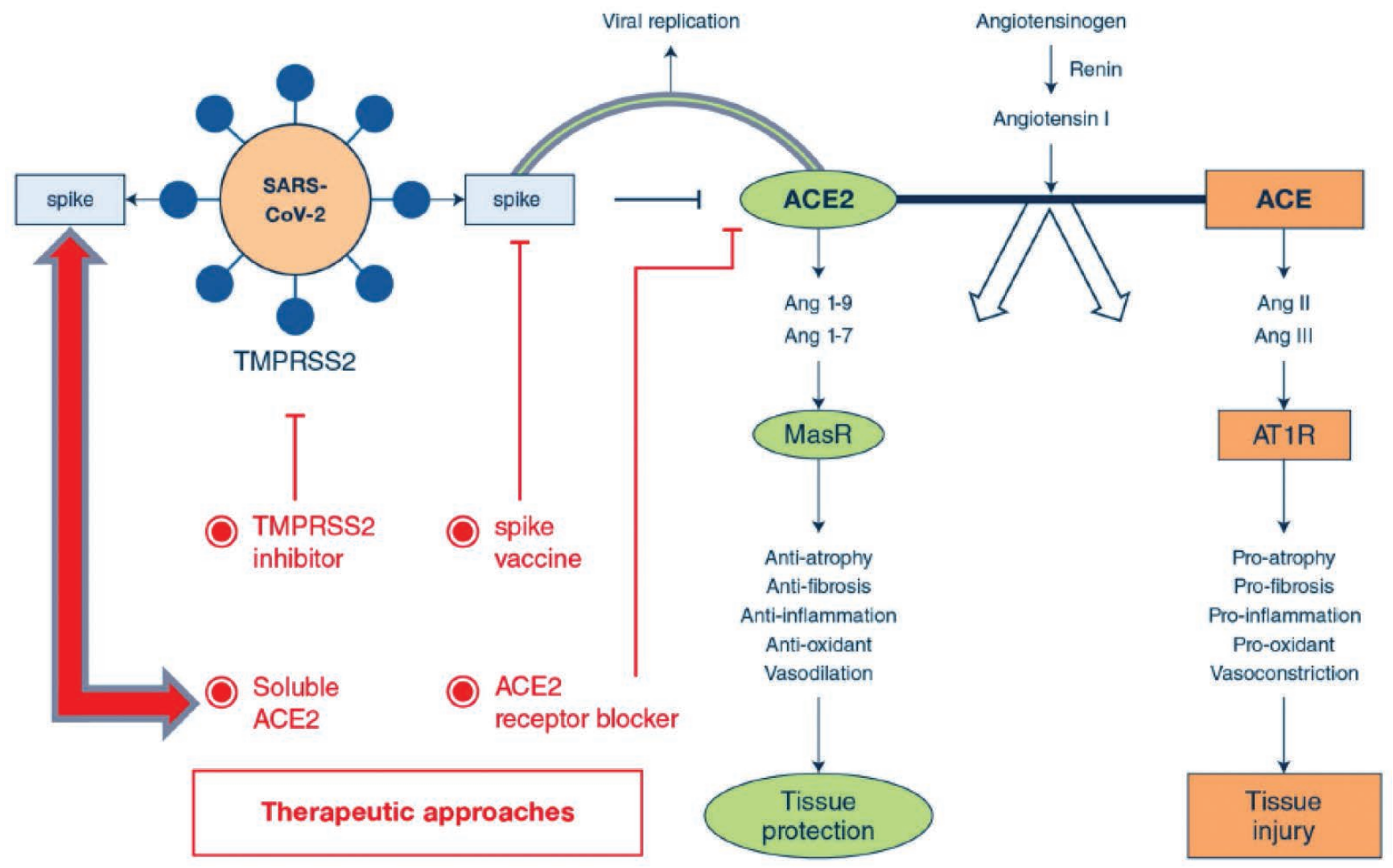

Figure 1. Potential approaches to address ACE2-mediated COVID-19 following SARS-CoV-2 infection. Intensive Care Med 2020;46:586-90. doi: 10.1007/s00134-020-05985-9. Creative Commons licence (http://creativecommons.org/licenses/by-nc/4.0/). 


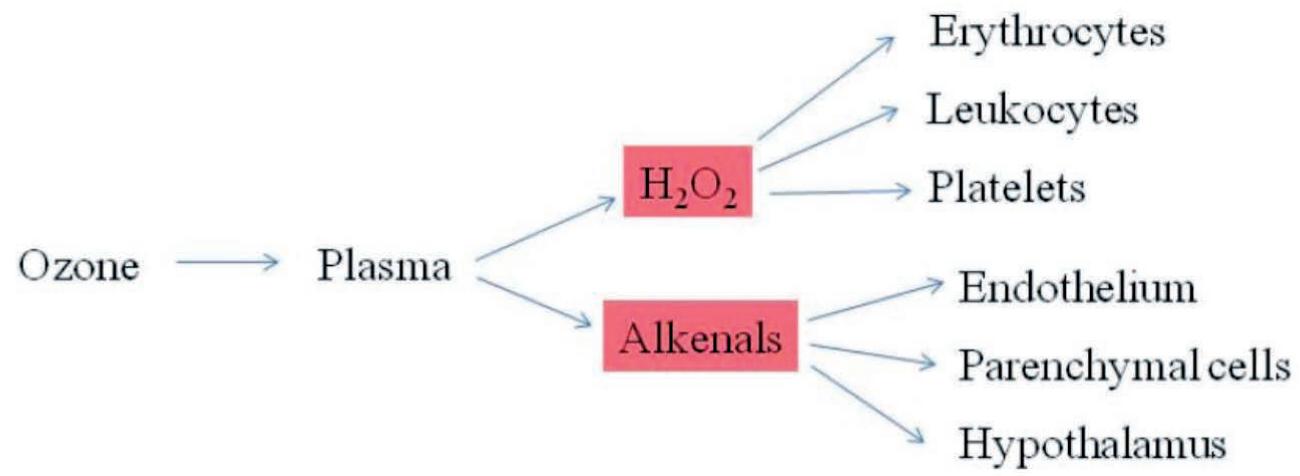

Figure 2. A scheme showing the reaction of ozone with plasma. The generated hydrogen peroxide triggers biochemical pathways in blood cells, while alkenals, after the infusion of ozonated blood into the donor, act on a variety of cells, upregulating the synthesis of many antioxidant proteins. Med Gas Res 2011;1:29. doi: 10.1186/2045-9912-1-29. Creative Commons licence (http://creativecommons.org/licenses/by-nc/4.0/).

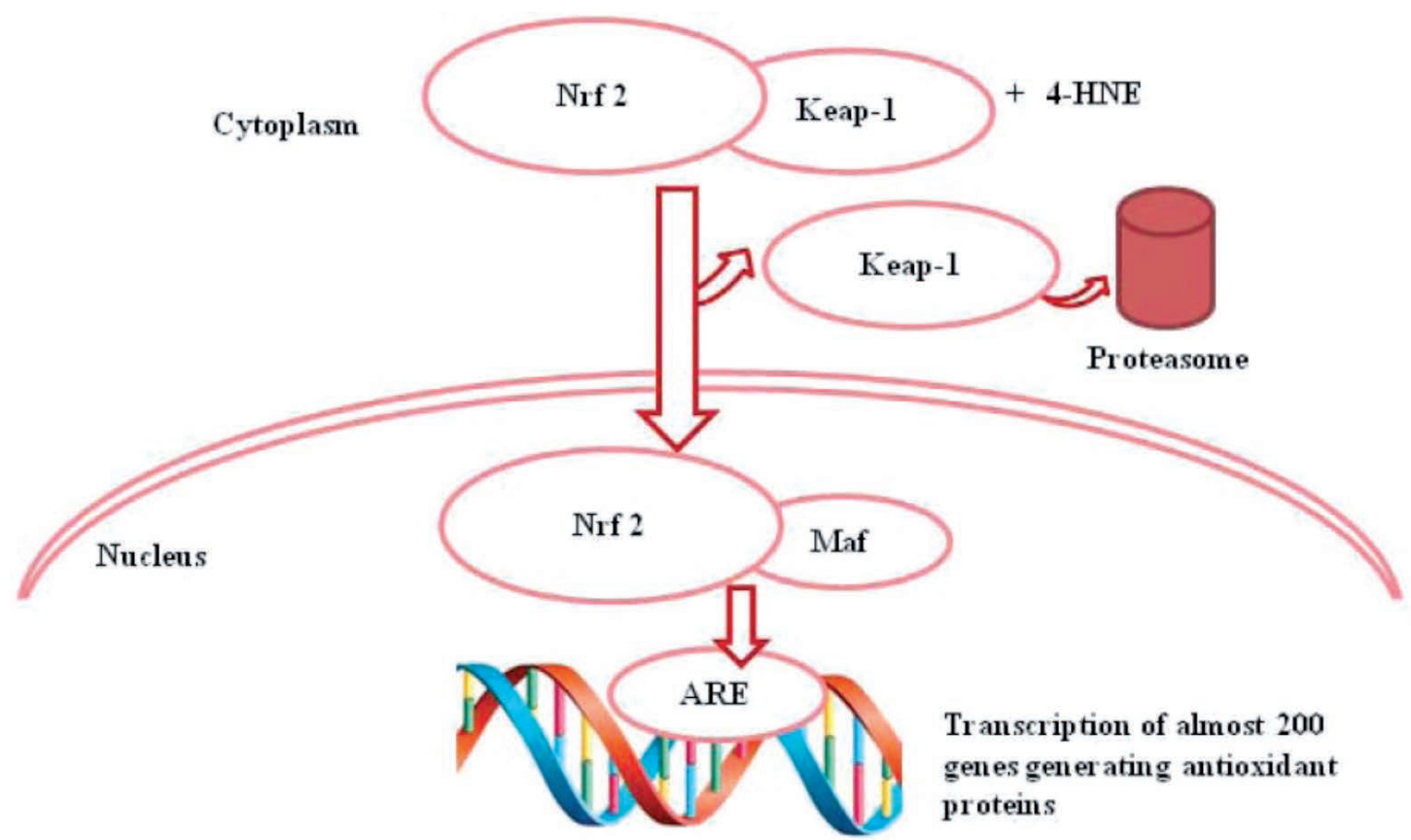

Figure 3. The transcription factor Nrf2 bound to Keap-1 activated by alkenals. The released Nrf2 traslocates into the nucleus and, after binding to Maf, docks on ARE and activates a number of genes leading ro the synthesis of antioxidant proteins. Med Gas Res 2011;1:29. doi: 10.1186/2045-9912-1-29. Creative Commons licence (http://creativecommons.org/licenses/by-nc/4.0/).

2018 demonstrated that ozone oxidative treatment protects the lung from IRI by attenuating nucleotide-binding oligomerization domainlike receptor containing pyrin domain 3 (NLRP3)-mediated inflammation, enhancing the antioxidant activity of Nrf2 and inhibiting apoptosis. ${ }^{17}$

In conclusion, as systemic oxygen therapy has all these positive effects: control of inflammation, stimulation of immunity, antivirus ability, protection from ischemia-reperfusion damage, action on proteasome and inflammation. ${ }^{7,9}$ Oxygen-ozone therapy can be said to be a new method of immunoceutical therapy and therefore its use in combination with other treatments in COVID19 positive patients may be justified, helpful and synergic.

Further studies and tests are needed, but we hope to soon have confirmation that $\mathrm{O}_{2} \mathrm{O}_{3}$ therapy is synergistic and effective in controlling COVID-19-infection.

\section{References}

1. Hotchkiss RS, Opal SM. Activating immunity to fight a foe A new path. N Engli J Med 2020;382:1270-2. doi: 10.1056/ NEJMcibr1917242.

2. Giuliani G, Ricevuti G, Galoforo A, Franzini M. Microbiological aspects of ozone: bactericidal activity and antibiotic/antimicrobial resistance in bacterial strains treated with ozone. doi: 10.4081/ozone.2018.7971

3. Remondino M. The use of ozone as a driver for economic and environmental sustainable development. doi: 10.4081/ozone. 2018.7806

4. Pandolfi S, Zammitti A, Franzini M, Simonetti V, Liboni W, Valdenassi L, Molinari F. Oxygen-ozone therapy in prevention 
and rehabilitation of myocardium infarct. doi: 10.4081/ ozone. 2018.7512

5. Wan Y, Shang J, Graham R, et al. Receptor recognition by the novel Coronavirus from Wuhan: an analysis based on decadelong structural studies of SARS Coronavirus. J Virol 94:e00127-20. doi: 10.1128/JVI.00127-20.

6. Allorto N. Oxygen-ozone therapy: an extra weapon for the general practitioners and their patients. doi: 10.4081/ ozone. 2019.8424

7. Bonforte G, Riva H, Giannini H, Balestra B. Treatment with oxygen-ozone therapy in hemodialysis patients. doi: 10.4081/ ozone. 2019.8376

8. Remondino M, Valdenassi L, Franzini M. Pharmacoeconomic analysis of ozone therapy supported by agent based process simulation and data mining. doi: 10.4081/ozone.2018.7518

9. Valdenassi L, Franzini M, Simonetti V, Ricevuti G. Oxygenozone therapy: paradoxical stimulation of ozone. doi: 10.4081/ ozone.2016.5837

10. Zhang H, Penninger JM, Li Y, et al. Angiotensin-converting enzyme 2 (ACE2) as a SARS-CoV-2 receptor: molecular mechanisms and potential therapeutic target. Intensive Care Med 2020;46:586-90. doi: 10.1007/s00134-020-05985-9.

11. Dosch SF, Mahajan SD, Collins AR. SARS coronavirus spike protein-induced innate immune response occurs via activation of the NF-kappaB pathway in human monocyte macrophages in vitro. Virus Res 2009;142:19-27. doi: 10.1016/j.virusres.2009.01.005.

12. Bocci V, Zanardia I, Valacchi G, et al. Validity of oxygenozone therapy as integrated medication form in chronic inflammatory diseases. Cardiovasc Hematol Disord Drug Targets 2015; 15:127-38

13. Smith NL, Wilson AL, Gandhi J, et al. Ozone therapy: an overview of pharmacodynamics, current research, and clinical utility. Med Gas Res 2017;7:212-9. doi: 10.4103/20459912.215752.

14. Sagai M, Bocci V. Mechanisms of action involved in ozone therapy: is healing induced via a mild oxidative stress? Med Gas Res 2011;1:29. doi: 10.1186/2045-9912-1-29.

15. Diaz-Luis J, Menendez-Cepero S, Diaz-Luis A, AscanioGarcia Y. In vitro effect of ozone in phagocytic function of leucocytes in peripheral blood. JO3T 2015;1. Available from: https://ojs.uv.es/index.php/JO3T/article/view/10627/html.

16. Yu G, Bai Z, Chen Z, et al. The NLRP3 inflammasome is a potential target of ozone therapy aiming to ease chronic renal inflammation in chronic kidney disease. Int Immunopharmacol 2017;43:203-9. doi: 10.1016/j.intimp.2016.12.022

17. Wang Z, Zhang A, Meng W, et al. Ozone protects the rat lung from ischemia-reperfusion injury by attenuating NLRP3-mediated inflammation, enhancing Nrf2 antioxidant activity and inhibiting apoptosis. Eur J Pharmacol 2018;835:82-93. doi: 10.1016/j.ejphar.2018.07.059. 